\title{
Studies of a rice sterile mutant sstl from the TRIM collection
}

\author{
Chia-Ling Chang ${ }^{1,2}$, Jerry C. Serapion ${ }^{2}$, Han-Hui Hung ${ }^{3}$, Yan-Cheng Lin ${ }^{4}$, Yuan-Ching Tsai ${ }^{5}$, Wann-Neng Jane ${ }^{2}$, \\ Men-Chi Chang ${ }^{1}$, Ming-Hsin Lai ${ }^{3}$ and Yue-ie C. Hsing ${ }^{12^{*}}$
}

\begin{abstract}
Background: Rice (Oryza sativa) is one of the main crops in the world, and more than 3.9 billion people will consume rice by 2025 . Sterility significantly affects rice production and leads to yield defects. The undeveloped anthers or abnormal pollen represent serious defects in rice male sterility. Therefore, understanding the mechanism of male sterility is an important task. Here, we investigated a rice sterile mutant according to its developmental morphology and transcriptional profiles.

Results: An untagged T-DNA insertional mutant showed defective pollen and abnormal anthers as compared with its semi-sterile mutant (sst) progeny segregates. Transcriptomic analysis of sterile sstl-s revealed several biosynthesis pathways, such as downregulated cell wall, lipids, secondary metabolism, and starch synthesis. This downregulation is consistent with the morphological characterization of sstl-s anthers with irregular exine, absence of intine, no starch accumulation in pollen grains and no accumulated flavonoids in anthers. Moreover, defective microsporangia development led to abnormal anther locule and aborted microspores. The downregulated lipids, starch, and cell wall synthesis-related genes resulted in loss of fertility.
\end{abstract}

Conclusions: We illustrate the importance of microsporangia in the development of anthers and functional microspores. Abnormal development of pollen grains, pollen wall, anther locule, etc. result in severe yield reduction.

Keywords: Anther development, Microspores, Transcriptomic analysis, Semi-sterile, Sterility

\section{Background}

Rice (Oryza sativa) is one of the most important staple crops in the world and is also an economical and cultivated food in Asia. One of the major limitations in rice yield production is sterility. Several studies provided strong evidence that male sterility was a serious defect in rice production and led to significantly decreased rice production (Thangasamy et al. 2011; Wang et al. 2013; Guo et al. 2013; Pu et al. 2017) or even almost complete loss (Liu et al. 2010; Ko et al. 2014; Yang et al. 2014; Li et al. 2016).

Male sterility is associated with a series of anther development steps and/or pollen maturation at the rice reproductive stage. Studies of the developmental morphology of pollen revealed several important steps,

\footnotetext{
*Correspondence: bohsing@gate.sinica.edu.tw

${ }^{1}$ Department of Agronomy, National Taiwan University, Taipei 106, Taiwan Full list of author information is available at the end of the article
}

such as cell differentiation into microspores and circular anther locules, the formation of four specialized cell layers in the anther, meiosis of the pollen mother cell, microspores with a well-developed pollen wall, microspore mitosis, and intine establishment of mature pollen (Raghavan 1988; Zhang et al. 2011; Walbot and Egger 2016). Previous studies concluded that the process of pollen maturation in rice was initiated in the L1, L2 and L3 layers of the stamen primordia, and central archesporial (AR) cells were generated from the mitotic division in the L2 layer to develop the primary parietal cells (PPCs) and primary sporogenous cells (PSCs) (Zhang et al. 2011; Kelliher et al. 2014; Yang et al. 2018). After AR cells divide and differentiate to PSCs and PPCs, PSCs form as sporogenous cells and later generate microspores; PPCs divide and develop into secondary parietal layers (SPCs). The outer layer of SPCs becomes the endothecium and middle layer, 
and the inner layer becomes the tapetal cell (Zhang and Wilson 2009).

Receptor protein kinase (RPK) is important in regulating tapetal cells and microsporocytes during sporophytic generation. In Arabidopsis, a putative leucine-rich repeat receptor protein kinase (LRR-RPK) gene, EXCESS MICROSPOROCYTES1 (EMS1)/EXTRA SPOROGENOUS CELLS (EXS), participates in early division of the anther and microsporocyte cells to control tapetum and microsporocyte development (Cai and Zhang 2018; Verma 2019). TAPETUM DETERMINANT1 (TPD1) was found as a cysteine-rich protein ligand of EMS1. TPD1 interacts with the EMS1 LRR domain to generate precursors of tapetal cells by promoting cell division of inner SPCs; the developmental tapetum layer determines the number of sporogenous cells by suppressing proliferation (Huang et al. 2016). A rice protein binding cassette with the LRR-RLK protein MULTIPLE SPOROCYTE1 and its ligand TPD1like protein (OsTDL1A) is involved in PPC division to contribute SPCs for the middle layer and establish the tapetum. The anther with double mutated OSTDL1A and MULTIPLE SPOROCYTE1 genes illustrated a lack of middle layers and tapetum and increased the number of microsporocytes in the early development of pollen (Yang et al. 2016). On mitosis, primary sporogenous cells divide into secondary sporogenous cells and become pollen mother cells (PMCs). PMCs pass through meiosis to generate microspores. At the same time, programmed cell death (PCD) of the tapetum layer occurs during meiosis. Several regulators respond to microspore generation, and PCD of tapetal cells such as a rice basic helix-loop-helix (bHLH) protein, TAPETUM DEGENERATION RETARDATION (TDR), controls tapetum degeneration to contribute to microspore development (Li et al. 2006). Gibberellic acid-inducible transcription factor GAMYB upregulates TDR1 expression, and a frame shift with a $C$ deletion of the allele gamyb-4 did not go through normal meiosis or PCD of tapetum in rice (Liu et al. 2010). The bHLH142 that conjugates with TDR1 turned on the downstream gene ETERNAL TAPETUM1 (EAT1) to organize microspore development. With T-DNA insertion into bHLH142, the tapetal PCD and microspore development were defective in anthers of rice loss-of-function bhlh142 (Ko et al. 2014).

Microspores are produced after PMC meiosis, and young microspores are released from the tetrads later. The rice Wax-deficient anther 1 (Wda1) defective mutant showed a significant defect of very-long-chain fatty acids in the anther epidermis and pollen wall that led to a severe absence of pollen (Jung et al. 2006).
Thus, the fatty acid of pollen wall conformation plays an important role in microspore maturation.

The pollen wall is composed of the outer pollen wall exine and inner wall intine. Transmission electron microscope (TEM) observation revealed that exine consists of the tectum, bacula, and nexine together as a bridge-like structure of the pollen outer wall (Shi et al. 2015). The pollen walls of microspores are constructed during tapetum layer degradation and again indicate the importance of lipid metabolism (Li et al. 2011). Transcriptomic analysis revealed that transcripts encoding cytochrome P450, acyltransferases, and lipid transfer proteins are produced from the tapetum secretion stage to support fatty acid accumulation and transportation to build exine (Huang et al. 2009). Without PCD, tapetum did not degenerate to generate fatty acid components such as sporopollenin for exine formation. Rice PERSISTENT TAPETAL CELL1 (PTC1), which affects fatty acid synthesis in the exine structure, promotes tapetum degradation to generate sporopollenin for pollen wall development ( $\mathrm{Li}$ et al. 2011). Scanning electron microscopy (SEM) revealed that the tapetal cell also produces orbicules during tapetum degeneration, which surround the surface of the tapetum layer, and orbicules provided the fatty acid product for assembly of sporopollenin for exine (Daku et al. 2016; Ruggiero and Bedini 2018). A rice lipid transfer protein OsC6 involved in lipid transfer from tapetum to exine is regulated by $b H L H, T D R$, and GAMYB. The truncated osc6 mutation resulted in defective orbicules and disordered exine structure in the pollen wall (Zhang et al. 2010). Thus, a well-developed exine is an indicator of maturation of microspore fertility during anther development.

The biosynthesis of sporopollenin is modified by several enzymes such as in-chain fatty acid hydroxylase (AtCYP703A2; OsCYP703A3), fatty acid $\omega$-hydroxylase (AtCYP704B1; OsCYP704B2), polyketide synthase (OsPKS1), tetraketide reductase (OsTKPR1), fatty acid anther-specific acyl-CoA synthetase (ACOS; OsACOS12), and reductase (OsDPW) in fatty acid metabolism (Li et al. 2010, 2016; Choi et al. 2011; Wang et al. 2013; Yang et al. 2014; Daku et al. 2016). These enzymes participate in a series of steps to convert fatty acid acyl$\mathrm{CoA}$ to the final sporopollenin product, which is then transported by $\mathrm{ABC}$ transporters such as ABCG26/ WBC27, OsABCG3 and lipid transfer protein OsC6 from the tapetum to exine for pollen wall utilization (Zhang et al. 2010; Choi et al. 2011; Chang et al. 2018). The intine of the pollen wall consists of carbohydrate polysaccharides, which are converted from UDP-glucose (Shi et al. 2015). The intine formation of rice is controlled by Golgilocalized GLYCOSYLTRANSFERASE1 (OsGT1), which 
transfers UDP-glucose for polysaccharide composition requirement, and also regulates starch and protein synthesis in pollen grain maturation to determine rice fertility (Moon et al. 2013). The polysaccharides of intine also regulate water content in pollen dehydration and disperse pressure when mature pollen spores expand with internal content accumulation (Xu et al. 2016).

Taiwan Rice Insertional Mutagenesis (TRIM) was initiated in 2002. In this mutant population, 93,000 rice mutated lines were created by T-DNA insertion by using a japonica variety, Tainung 67 (Wu et al. 2017). The reverse genetics approach provided a large-scale population of T-DNA mutagenesis screening for comparing phenotypic characterization and rice genomic function. The TRIM population was used in two studies on malesterile mutants. T-DNA insertion into bHLH142 led to no response to PCD of tapetum, and this gene was regulated by the early tapetum developing-related genes UNDEVELOPED TAPETUM1 (UDT1) and GAMYB, then was responsible for downstream TDR1 and EAT1 regulation (Ko et al. 2014). Another TRIM mutant study indicated that a rice SUMO E3 ligase SIZ1 participated in controlling endothecium development during anther dehiscence to manipulate the fertility of rice. Mutant siz1 showed the inability of anther dehiscence and no cavity of two adjacent locules; thus, it released no pollen grains during anthesis. In addition, this mutant had a shorter plant with few tillers and low seed set rate (Thangasamy et al. 2011).

Here we report a morphological characterization of a male sterile mutant from the TRIM collection and investigate the mechanism of sterility. We illustrate the importance of microspore fertility in anther development and the functional biosynthesis of microspores. We also performed a comparative transcriptomic analysis between fertile and sterile anthers to prove that fatty acid biosynthesis pathways participate in the morphology of pollen wall formation.

\section{Methods}

\section{Plant materials and growth condition}

T-DNA insertional mutant line M0037841 with $30 \mathrm{~T}_{2}$ seeds were obtained from the TRIM collection and grown at the genetically modified plant isolation field (GM field) in the Taiwan Agricultural Research Institute (TARI) for agronomic trait evaluation. Leaf samples from individual plants of the $T_{2}$ population were harvested and frozen under liquid nitrogen for genomic DNA extraction experiments. Progeny from the semi-sterile line of M0037841 were both grown in the TARI GM qualified field or a growth chamber under day $28{ }^{\circ} \mathrm{C} /$ night $25{ }^{\circ} \mathrm{C}$, $16 \mathrm{~h}$ of light and $80 \%$ humidity at Academia Sinica, Taipei. Yield component analysis including panicle number, grain number, fertility rate, and grain weight was performed by the semi-sterile segregates in the TARI GM field. The anther samples for floral morphology observation, pollen viability assay, gene expression analysis, phenotypic characterization of cross-sections, TEM and SEM were collected from plants grown in the growth chamber.

\section{Genomic DNA extraction and PCR-based genotyping}

Genomic DNA was extracted from leaves by using the Wizard Genomic DNA purification kit (Promega Corporation, Madison, WI, USA). All T-DNA mutagenesis plants from $\mathrm{T}_{2}$ were identified by T-DNA tagging regions, a T-DNA construct pTAG8, such as hygromycin phosphotransferase gene (HPT), GUS gene, and CaMV35S enhancer with PCR-based genotyping assay. The PCR reaction in $20 \mu \mathrm{L}$ volume involved 50 ng genomic DNA, $0.2 \mu \mathrm{m}$ primers and Taq DNA Polymerase $2 \times$ Master Mix RED (Ampliqon, Herlev, Denmark) for amplification. The sequences of primers are in Additional file 1: Table S1.

\section{Pollen viability and germination analysis}

Mature pollen grains were collected before anthesis in the fertile, semi-sterile and sterile types from semi-sterile progeny segregates and stained with iodine-potassium iodide $\left(\mathrm{I}_{2}-\mathrm{KI}\right)$ solution for pollen viability. Pollen viability was evaluated by using pollen shape and staining for classification into four grades as dark black $(+++)$, partial black $(++)$, orange $(+)$ and yellow $(-)$. More than 2000 individual pollen grains were counted under a Zeiss AxioImager Z1 microscope. More than 1000 pollen grains per sample were co-cultured with $15 \%$ sucrose (Sigma-Aldrich, St. Louis, MO, USA), 5\% starch (SigmaAldrich, St. Louis, MO, USA), and $0.005 \%$ orthoboric acid (Merck, Darmstadt, Germany) at $28{ }^{\circ} \mathrm{C}$ for $30 \mathrm{~min}$ for detecting pollen tube germination rate.

\section{Morphological analysis of anther characterization}

Several reproductive growth parameters of development were revealed by kernel size, spikelet length, spikelet width, anther color, and anther length for 5 anther stages, young microspores stage (YM), vacuolated pollen stage (VP), early pollen mitosis stage (EpM), late pollen mitosis stage (LpM), and mature pollen stage (Mp) (Zhang and Wilson 2009; Huang et al. 2009). These five stages were equal to the anther stages from Zhang and Wilson (2009) reported in "stage 9", "stage 10", the first mitotic division of microspore in "stage 11", the second mitosis of microspore in "stage 12", and the spherical mature pollen grains in "stage 13". Anther samples of all developmental stages were fixed in $2.5 \%$ glutaraldehyde, $4 \%$ paraformaldehyde, and $0.1 \mathrm{M}$ sodium K-phosphate buffer $(\mathrm{pH} 7.0)$ at $4{ }^{\circ} \mathrm{C}$ 
for $24 \mathrm{~h}$. Then, after three rinses with $0.1 \mathrm{M} \mathrm{K}$-phosphate buffer ( $\mathrm{pH}$ 7.0) for $20 \mathrm{~min}$ each, samples were transferred to $1 \% \mathrm{OsO}_{4}$ in $0.1 \mathrm{M} \mathrm{K}$-phosphate $(\mathrm{pH} 7.0)$ for $4 \mathrm{~h}$ at room temperature. The samples were washed again with $0.1 \mathrm{M} \mathrm{K}$-phosphate buffer ( $\mathrm{pH} 7.0)$ as for the previous rinsed steps. Samples were dehydrated with an ethanol series and propylene oxide, and embedded in Spurr resin. The cross sections were prepared in $1-\mu \mathrm{m}$ sections and stained with toluidine blue for anther transverse section detection and anther locule area investigation under a Zeiss AxioImager Z1 microscope. The ultrathin sections in 70-90 $\mathrm{nm}$ were stained with uranyl acetate and lead citrate for TEM imaging by using a Philips CM 100 TEM system at $80 \mathrm{kV}$. For cryo-SEM, anthers and pollen grains at Mp stage were frozen in liquid nitrogen and placed into the sample preparation chamber at $-160{ }^{\circ} \mathrm{C}$. After the temperature reached $-85^{\circ} \mathrm{C}$ and sublimation/ etching proceeded for $15 \mathrm{~min}$, samples were coated with platinum particles at $-130{ }^{\circ} \mathrm{C}$. Samples were moved to a cryo-stage SEM chamber and examined by using a CryoSEM system at temperature $-190{ }^{\circ} \mathrm{C}$ (Quanta 200 SEM/ cryo system Quorum PP2000TR FEI).

\section{RNA extraction and transcriptomic analysis}

Anther samples were collected from YM or LpM stages for total RNA isolation by using TRIzol reagent (Thermo Fisher Scientific, Wilmington, DE, USA), and $5 \mu \mathrm{g}$ total RNA was prepared for RNA sequencing. For RNA sequencing, single-end libraries were created and sequenced on an Illumina HiSeq 2000 system in 90-bp read length for 10 million reads per sample. Sequence data were deposited in the NCBI gene expression omnibus (accession no. GSE129579). RNA sequencing data were evaluated by RNA-seq analysis, differential expression of genes and heat map drawing with the CLC Genomics Workbench 11 (CLC Bio, QIAGEN Bioinformatics, Aarhus, Denmark). The RNA-seq transcripts were annotated by using the RAP-DB database (https:// rapdb.dna.affrc.go.jp/index.html) and compared with the Rice Expression Profile Database (http://ricexpro.dna. affrc.go.jp/). Anther-specific transcriptomic genes were also confirmed by Rice Anther Expression Plots (https ://www.cpib.ac.uk/anther/riceindex.html). EXPath Tool (http://expathtool.itps.ncku.edu.tw/), Kyoto Encyclopedia of Genes and Genomes (KEGG) (http://www.genom e.jp/kegg/), and MapMen (https://mapman.gabipd.org/) were used for gene function prediction and analysis.

\section{Gene expression analysis}

Total RNA from YM and LpM were converted to cDNA with use of oligo (dT) primers by the SuperScript III First-Strand Synthesis System (Thermo Fisher Scientific, Wilmington, DE, USA). Real-time quantitative RT-PCR was performed with the SYBR Green-based quantitative PCR method by mixing $20 \mathrm{ng}$ cDNA, $0.25 \mu \mathrm{m}$ primers and fluorescence Power SYBR Green PCR Master Mix (Applied Biosystems, Foster City, CA, USA) for gene expression detection. The gene expression was calculated by the $2^{-\triangle \Delta C t}$ method with OsUBI, OsACT11, OsUBQ5, and $e E F-1 \alpha$ used as internal control genes. All primer sequences are in Additional file 1: Table S1.

\section{Results}

\section{A semi-sterile mutant from TRIM collection}

Sterility is one of the important regulators of the reproductive stage in rice yield production. To study this phenomenon of sterility, we selected the T-DNA insertional mutant line M0037841 from the TRIM collection. Thirty $\mathrm{T}_{2}$ seeds of M0037841 were grown in a GM field in TARI. The $\mathrm{T}_{2}$ population in M0037841 was identified without co-segregation between the phenotype of sterility and the T-DNA insertional event of the genome (Additional file 2: Table S2).

From the developmental morphology of the $\mathrm{T}_{2}$ population in M0037841, we noticed two plants were semisterile and thus designated them semi-sterile (sstl) for the rest of the study (Additional file 2: Table S2). From the progeny segregates of the mutant $s s t l$, characteristic distributions of fertility were classified as fertile panicle plants $(S S T L-F)$, semi-sterile panicle plants (sstl-ss), and sterile panicle plants (sstl-s) (Fig. 1a-c). In sstl progeny segregates, SSTL-F and sstl-s lines did not differ in plant height or tiller number during the vegetative stage (Additional file 3: Figure S1). In the reproductive stage, yield component traits were analyzed as fertility rate, number of panicles, grain number and grain weight in $S S T L-F$, sstl-ss, and sstl-s. The fertility rate of $s s t l-s s$ was 49.2\% (Table 1), showing half fertile seeds per panicle (Fig. 1c). SSTL-F, sstl-ss, and sstl-s all had 15 panicles per plant, but the grain number of each panicle gradually increased from $S S T L-F$ and $s s t l-s s$ to $s s t l-s$. The grain size from fertile and sterile spikelets did not differ. The kernel shape, along with palea and lemma, did not differ (Fig. 1d).

Thus, the sterile characterization of sstl-s was not caused by a T-DNA insertion, and sstl-s still inherited the sterility trait from the progenitor semi-sterile $s s t l$.

\section{Sterility from sstl-s pollen viability}

To understand the sterility of rice mutant $s s t l-s$, we investigated the floral morphology of SSTL-F and sstl-s. During pollen maturation, the flower of sstl-s exhibited a white anther, indicating lack of flavonoid components (Fig. 2a, b). Mature pollen grains released from anthers of SSTL$F$ and (above) and sstl-s (below) showed a white color in sstl-s (Fig. 2c). Pollen grains from sstl-s were so tightly 

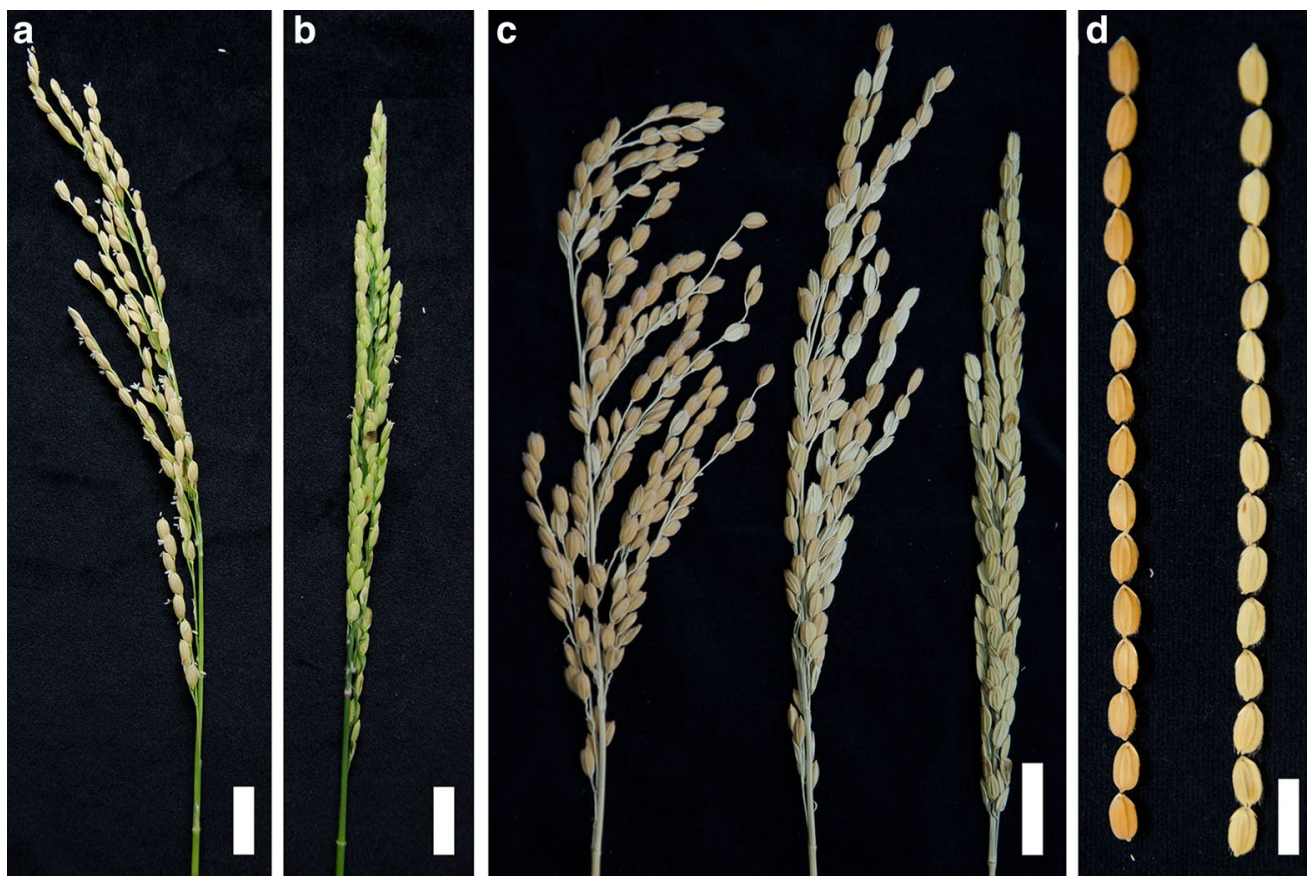

Fig. 1 Phenotypic characterization of segregants of the semi-sterile mutant (sst/). a Plants with fertile panicles; $\mathbf{b}$ completely sterile panicles; $\mathbf{c}$ three types of fertility in the sst/ progeny segregates: from left to right as fertile, semi-sterile, and sterile. Bar $=2 \mathrm{~cm}$. $\mathbf{d}$ Seed size between fertile and sterile indicated. $\mathrm{Bar}=1 \mathrm{~cm}$

\begin{tabular}{lllll}
$\begin{array}{l}\text { Table } 1 \text { Yield } \\
\text { segregates }\end{array}$ & component & analysis of & sstl & progeny \\
\hline Phenotypes & AFRP (\%) & ANP & ANGP & AGWP (g) \\
\hline SSTL-F & $92.80 \mathrm{a}$ & $15.71 \mathrm{a}$ & $148.43 \mathrm{ab}$ & $4.01 \mathrm{a}$ \\
sstl-sS & $49.20 \mathrm{~b}$ & $15.43 \mathrm{a}$ & $163.67 \mathrm{~b}$ & $2.57 \mathrm{~b}$ \\
sstl-s & $0.07 \mathrm{C}$ & $15.14 \mathrm{a}$ & $179.71 \mathrm{bc}$ & $0.96 \mathrm{C}$ \\
\hline
\end{tabular}

Yield component analysis of three types in sst/ progeny segregates. $F$ fertile, ss semi-sterile, $s$ sterile, $A F R P$ average fertility rate per panicle, $A N P$ average number of panicles per plant, $A N G P$ average number of grains per panicle, $A G W P$ average grain weight per panicle. The statistical analysis was performed by one-way ANOVA with Tukey test post hoc analysis. Data were collected from 7 individua plants in each type and presented as mean \pm SEM

Values followed by different letters indicated a significant difference for each variable $(P \leq 0.05)$

stuck to anther locules that they may not be exposed easily as mature pollen in $S S T L-F$ after cutting the anthers (Fig. 2c). During anthesis in SSTL-F, the mature pollen grains were released from anther dehiscence and the filaments elongated. However, only elongated filaments were found in sstl-s (Fig. 2d). The anther locules of sstl-s were juicy and sticky and thus the pollen grains were barely released after filament elongation. This finding was consistent with the anther locules of $s s t l-s$ after chopping (Fig. 2c, d). By SEM observations of SSTL-F and sstl-s anthers, we confirmed that sstl-s had a shrinking anther and smaller pollen sac as compared with SSTL-F
(Fig. 2e-h). Additionally, the pollen grains of $s s t l-s$ did not fill up with content and formed a stomatocyte-like shape during maturation (Fig. $2 \mathrm{~g}-\mathrm{j}$ ). The pollen sacs of sstl-s had no surrounding pollen grains on anther locules because pollen grains of sstl-s did not form as spherical as compared with mature pollen of SSTL-F (Fig. 2g, h).

Pollen viability and pollen tube germination analyses were performed to determine the severity of defective pollen in sstl-s. Because mature pollen grains contained abundant starch to provide energy for supporting pollen maturation and pollen tube germination (Lee et al. 2016), we studied pollen viability by using $I_{2}-K I$ staining. Figure $2 \mathrm{k}$ showed a significant difference between mature pollen grains of SSTL-F (left) and sstl-s (right) in pollen viability, as indicated by staining color and pollen spherical shape. The starch accumulation of these pollen grains was illustrated as dark black $(+++)$, partial black $(++)$, orange $(+)$ and yellow $(-)$ after $\mathrm{I}_{2}-\mathrm{KI}$ staining (Fig. 2l). The proportion of dark-black mature pollen in SSTL-F, sstl-ss, and sstl-s was $96 \%, 64 \%$, and $0.35 \%$, respectively, revealing low pollen viability in the sterile mutant (Fig. 2l). Besides, sstl-ss showed 18\% partial black pollen, with none in SSTL-F and sstl-s. The proportion of dark-black pollen in semi-sterile sstl-ss was about $60 \%$ and agreed well with half fertile seeds per panicle in sstlss (Table 1 and Fig. 21). In addition, examination of pollen-tube germination of fertile and sterile pollen grains 

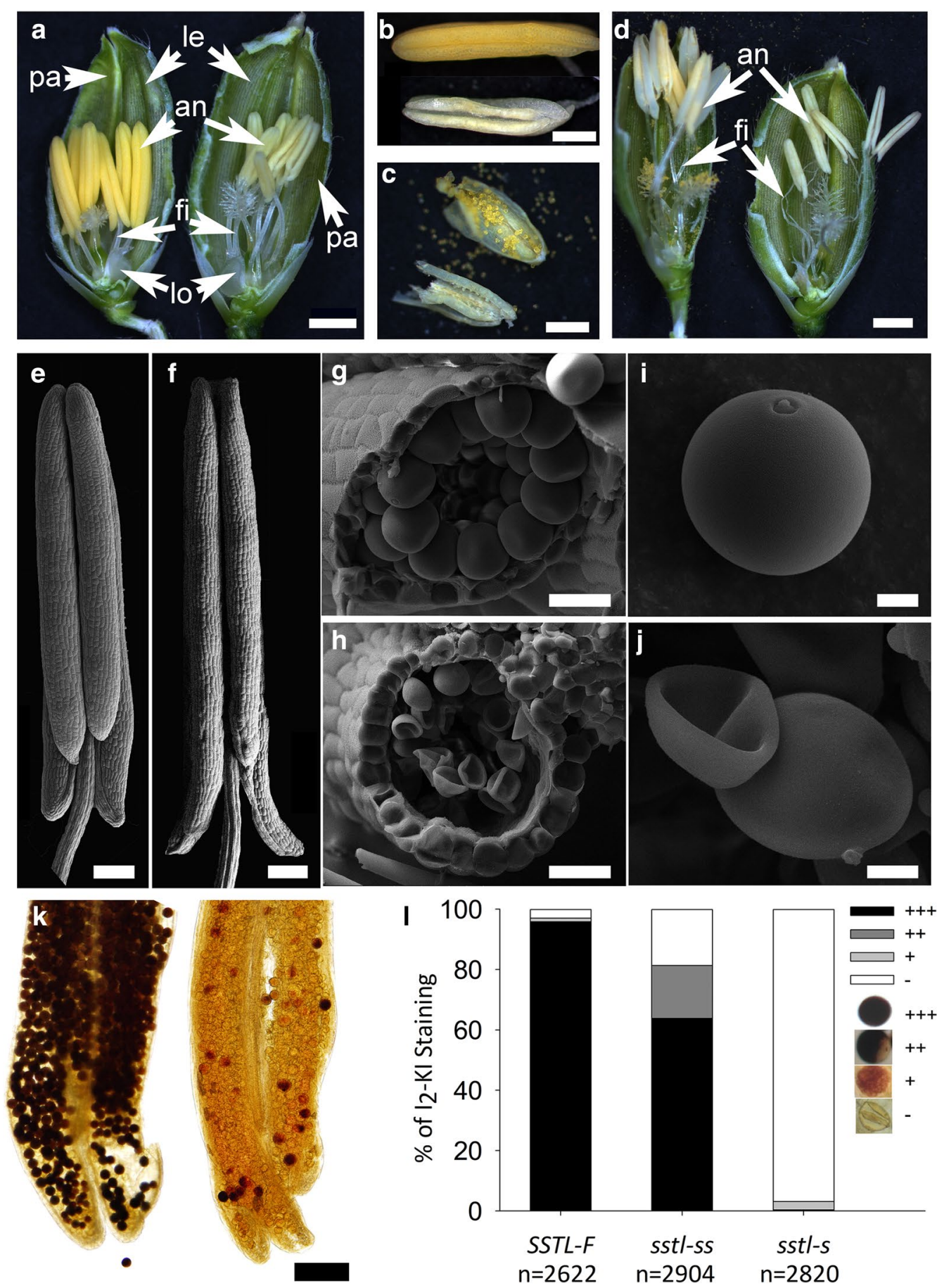

Fig. 2 Floral morphology of fertile and sterile plants from sstl offspring. a The floral structure between SSTL-F (left) and sstl-s (right) at heading stage. Bar $=1 \mathrm{~mm}$. $\mathbf{b}$ The exterior of anther in SSTL-F (above) and sstl-s (below). Bar $=0.4 \mathrm{~mm}$. c Mature pollen was presented after chopping the anthers of SSTL-F (above) and sstl-s (below). Bar $=0.4 \mathrm{~mm}$. d Filament elongation of SSTL-F (left) and sstl-s (right) during anthesis. Bar $=1 \mathrm{~mm}$. e, $\mathbf{g}$, i SEM observation of SSTL-F and $\mathbf{f}, \mathbf{h}, \mathbf{j}$ sstl-s in anther and pollen. $\mathbf{e}, \mathbf{f}$ Bar $=0.2 \mathrm{~mm} ; \mathbf{g}-\mathbf{j}$ bar $=50 \mu \mathrm{m}$. $\mathbf{k} \mathrm{I}_{2} \mathrm{Kl}$ staining of SSTL-F (left) and sst-s (right). $\mathrm{Bar}=200 \mu \mathrm{m}$. I Pollen viability in different maturity types of SSTL-F, sstl-ss, and sstl-s. an anther, fifilament, le lemma, lo lodicule, pa palea 
confirmed an $81.7 \%$ germination rate in SSTL-F but only $0.26 \%$ in sstl-s (data not shown).

The defects in sstl-s pollen reveal that its anther locules did not undergo anther dehiscence because the pollen sacs did not expand and pollen grains did not form a spherical shape. Almost zero percentage of pollen viability and pollen germination rates were consistent with the sterility of the mutant sstl-s as well as pollen-defective morphology.

\section{Anther morphology of sstl-s}

Cross sections of anthers in SSTL-F and sstl-s at specific anther development stage provided tools to understand male sterility. At YM stage, both SSTL-F and sstl-s had four cell layers (i.e., epidermis, endothecium, middle layer, and tapetum) (Fig. 3a, f, k). Microspores were released from tetrads by callose degradation in SSTL-F (Fig. 3a) but few from sstl-s anthers (Fig. 3f, k). The tapetum layer started degenerating and the microspores formed vacuolated as an oval shape in SSTL-F anthers (Fig. 3b). Tapetum layers of sterile sstl-s still degraded (Fig. 3g, 1), similar to the fertile line SSTL-F anther at VP stage. Later on, microspores went through the first mitosis and became bicellular pollen. The microspores were smaller from the EpM than VP stage and the starch began to accumulate in fertile microspores (Fig. 3c). Meanwhile, the tapetal cells were almost completely degenerated and left only a thin layer on the internal surface of the anther locule in SSTL-F (Fig. 3c). In contrast, the sstl-s anther showed a delay of tapetum degradation (Fig. 3h, $\mathrm{m}$ ) and a larger size of tapetal cell at the EpM stage. In the LpM stage, microspores differentiated into two sperm cells by the second mitosis division. $S S T L-F$ microspores contained a high amount of starch and lipid accumulation (Fig. 3d). The endothecium and epidermal cells of SSTL-F degenerated in the LpM stage (Fig. 3d), but sstl-s anthers contained defective pollen grains, and anther locules maintained a larger epidermis and endothecium cell as compared with fertile ones (Fig. 3i, n). The tapetum layer of SSTL-F degenerated and disappeared at this stage (Fig. 3d) but remained partially in the sstl-s anther because of delayed degradation (Fig. 3n). The final stage of microspore maturation was the formation of plump round mature pollen in SSTL-F
(Fig. 3e), but only defective pollen was produced in sstl$s$ anthers (Fig. 3j, o). The epidermis degenerated and became smaller than those from previous stages in the $S S T L-F$ anther. However, as compared with $s s t l-s$ anthers, the epidermal cells of $s s t l-s$ were three times larger than SSTL-F cells (Fig. 3j, o). The mutant sstl-s contained defective pollen and its anthers also contained almost no microspores in the developmental process. Microspores were barely generated in $s s t l-s$ anthers, and $s s t l-s$ showed undeveloped anther locules without PMCs in early-stage cross sections (Additional file 4: Figure S2). This abnormal anther locule illustrated that these anthers had no specialized four layers (i.e., epidermis, endothecium, middle layer, and tapetum) to form a circular anther locule. The functional PMCs were not produced to generate microspores in sterile sstl-s (Additional file 4: Figure S2). From TEM observations, only epidermal cells remained in these slender twig-like undeveloped anther locules (Additional file 4: Figure S2f, i).

To better understand the defective pollen of sterile sstl-s during pollen development, we used TEM analysis for the structure of anthers and microspores in the wild type and mutant. During VP stage, consistent with the previous studies, both tapetal cells of fertile SSTL-F and sterile sstl-s degenerated and thus promoted orbicule formation (Fig. 4a, d, g). The orbicules were constructed as a cone shape with the high electronic denseness of the tapetum inner side layer to provide a lipid component for the pollen exine (Zhang et al. 2010). The orbicule and pollen exine (at tectum, bacular and nexine) were darker under TEM, which indicates concentrated lipid accumulation. The orbicule and exine were much darker in fertile SSTL-F than sterile $s s t l-s$, which suggests less lipid content in the sstl-s anther (Fig. 4b, e, h). At LpM stage, the structure of exine was complete, shown as bridge-like, with ordered tectum, bacular and nexine (Fig. 4b), whereas the exine of sstl-s contained no space between the tectum and nexine, so it became a messy aggregation in exine (Fig. 4e). The other type of abnormal exine in sterile $s s t l-s$ was the defective bridge-like shape in the pollen wall (Fig. 4h). Mature pollen of fertile SSTL-F contained conspicuous intine (Fig. 4c), whereas intine was absent in sstl-s (Fig. 4i). Intine contains a high

\footnotetext{
(See figure on next page.)

Fig. 3 Cytological observation of cross sections from developing anthers. a Anthers at young microspore stage (YM) with epidermis, endothecium, middle layer, and tapetum layers of SSTL-F and $\mathbf{f}, \mathbf{k}$ sstl-s. b At vacuolated pollen stage (VP), when the microspores formed vacuolated in SSTL-F and g, I sstl-s. c At early pollen mitosis stage (EpM), when microspores went through the first mitosis and became bicellular pollen in SSTL-F and $\mathbf{h}, \mathbf{m}$ sstl-s. $\mathbf{d}$ At late pollen mitosis stage (LPM), when microspores went through the second mitotic division for two sperm cells in SSTL-F and $\mathbf{i}, \mathbf{n}$ Sstl-s. e At mature pollen stage (Mp), when microspores were in the plump roundness shape of SSTL-F and $\mathbf{j}$, o $S S t$-s. BP bicellular pollen, DP defective pollen, E epidermis, En endothecium, MP mature pollen, Msp microspore parietal cell, $T$ tapetum. Bars $=80 \mu \mathrm{m}$
} 


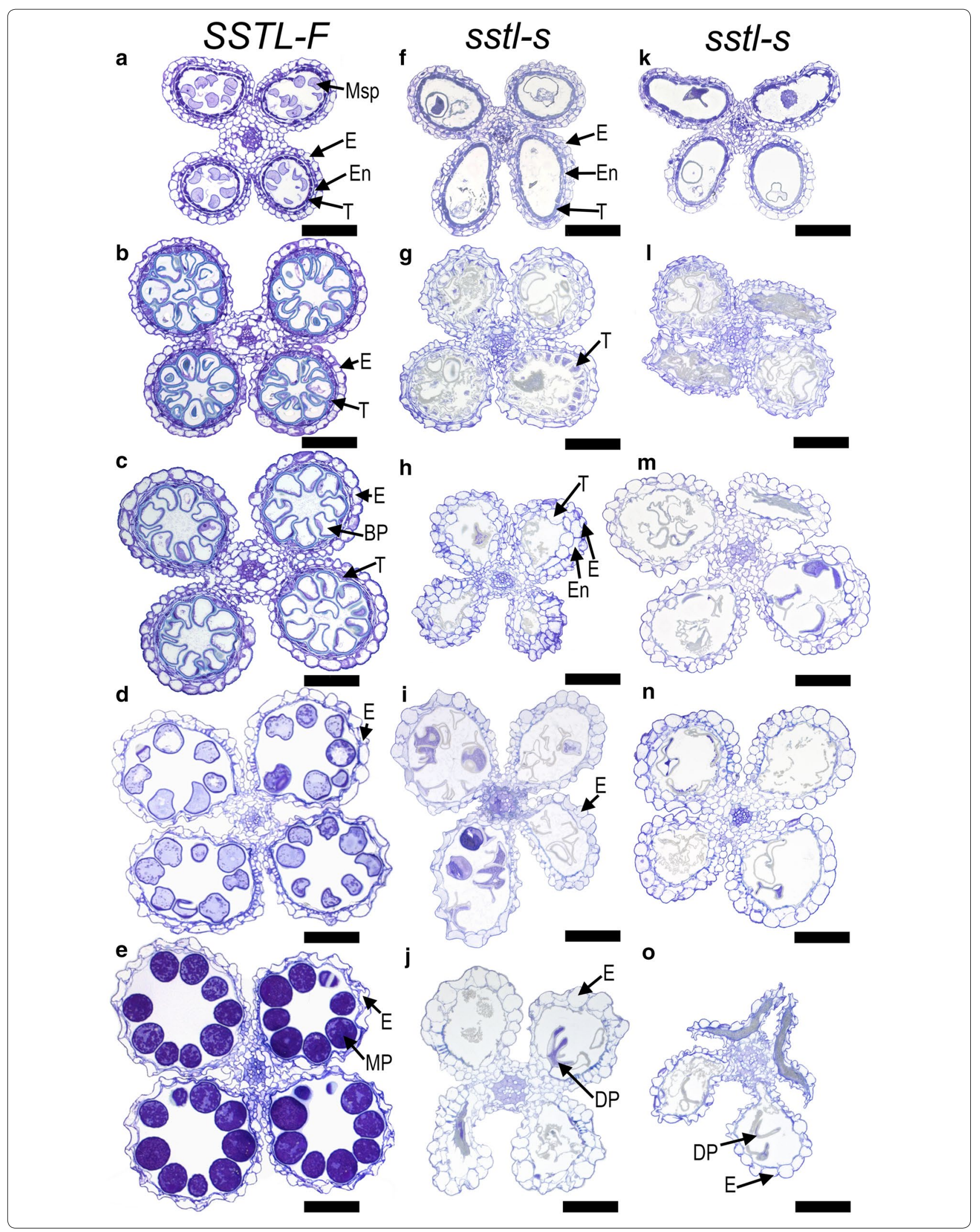



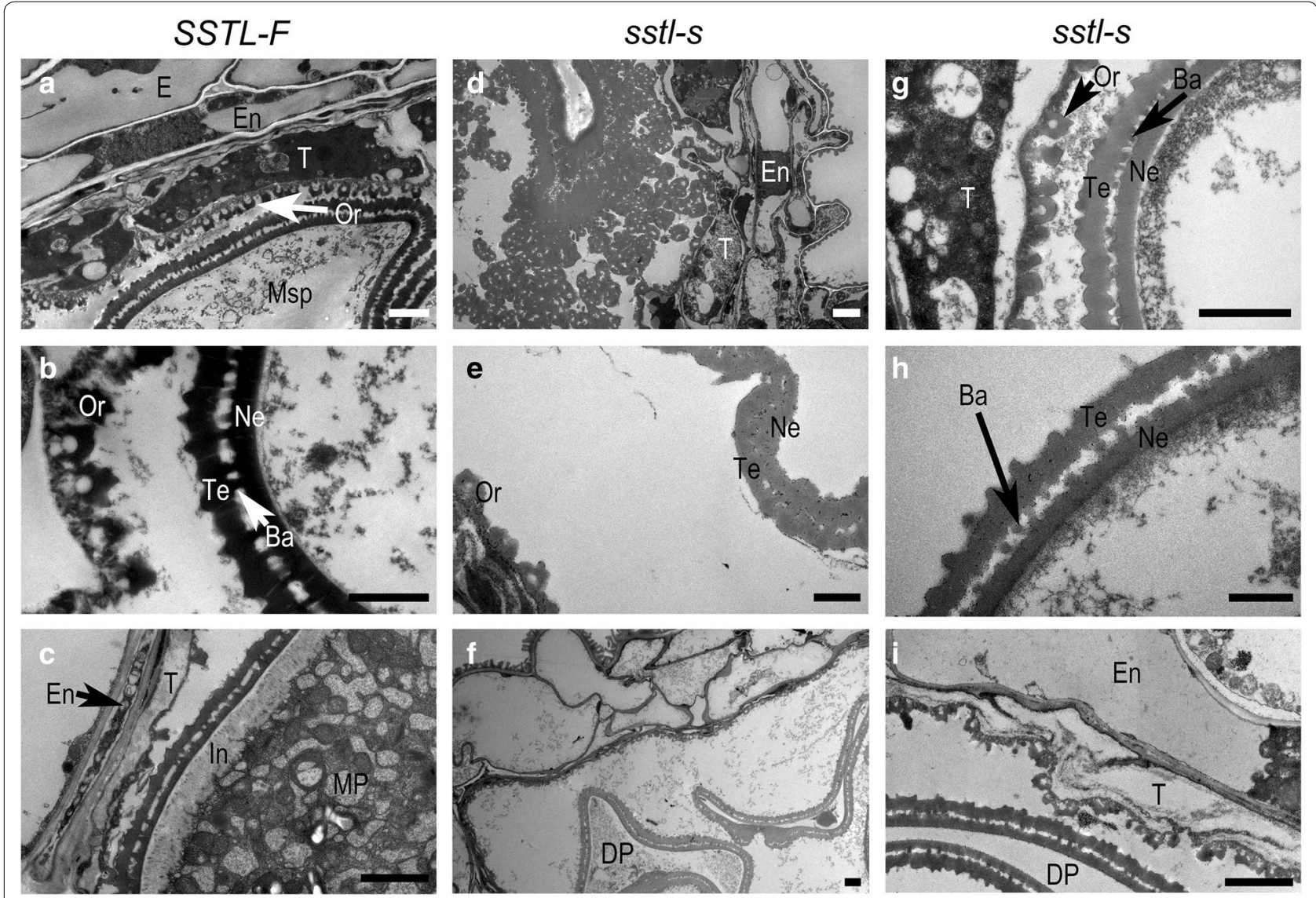

Fig. 4 TEM analysis of anther development in SSTL-F and sstl-s. a At vacuolated pollen stage (VP), when the tapetal cell was decomposed to generate orbicules in SSTL $F$ and $\mathbf{d}, \mathbf{g}$ SStl-s. Bars $=2 \mu \mathrm{m}$. $\mathbf{b}$ At late pollen mitosis stage (LpM), when the tapetum was degraded, and the pollen wall of microspores integrated completely in SSTL-F and $\mathbf{e}, \mathbf{h}$ sstl-s. Bars $=1 \mu \mathrm{m}$. c At mature pollen stage (Mp), when endothecium degenerated and microspores were in the plump round shape with puffy intine of SSTL-F and $\mathbf{f}, \mathbf{i} s s t l-s$. Bars $=2 \mu \mathrm{m}$. Ba Bacular, DP defective pollen, E epidermis, En endothecium, In intine, MP mature pollen, Msp microspore, Ne nexine, Or orbicule, T tapetum, Te tectum

amount of polysaccharides (Caffall and Mohnen 2009). In addition, intine formation is controlled by glycosyltransferase, and complete intine would determine the accumulation of starch, protein, and other important contents for mature pollen grain (Moon et al. 2013). Sterile $s s t l-s$ exhibited completely defective intine, leading to defective pollen grain accumulation at Mp stage (Fig. 4f, i). Besides, the endothecium and tapetum layers of fertile $S S T L-F$ decreased entirely to a thin surface at Mp stage (Fig. 4c) rather than the slight reduction in sstl-s anthers (Fig. 4i).

We measured the area of anther locule with more than 20 individual anthers for SSTL-F and sstl-s. The defective anther locules in sstl-s were less than half of those in $S S T L-F$ (Fig. 5). The minimum anther locule area of sstl-s was about $0.5 \times 1000 \mu \mathrm{m}^{2}$ at LpM and Mp stages and was

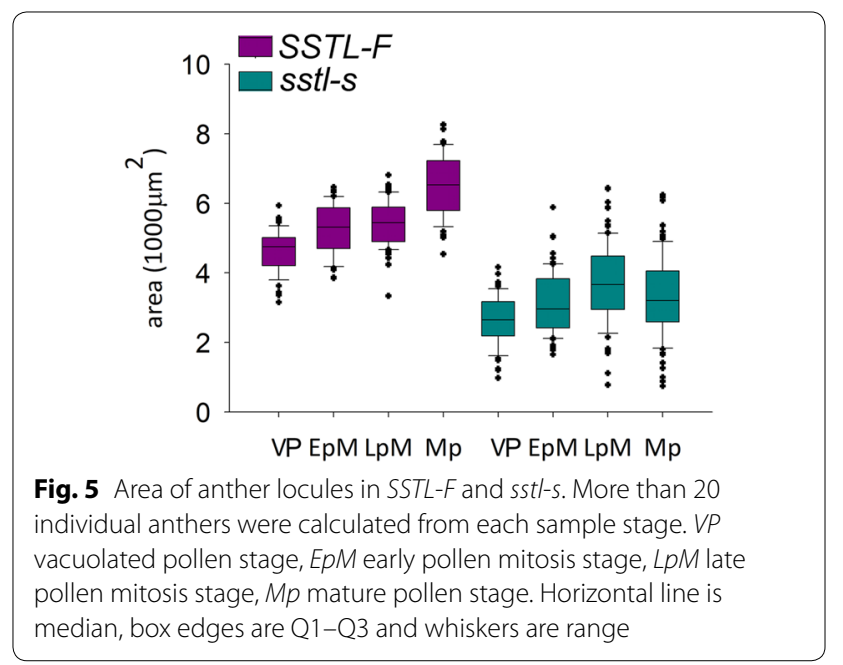




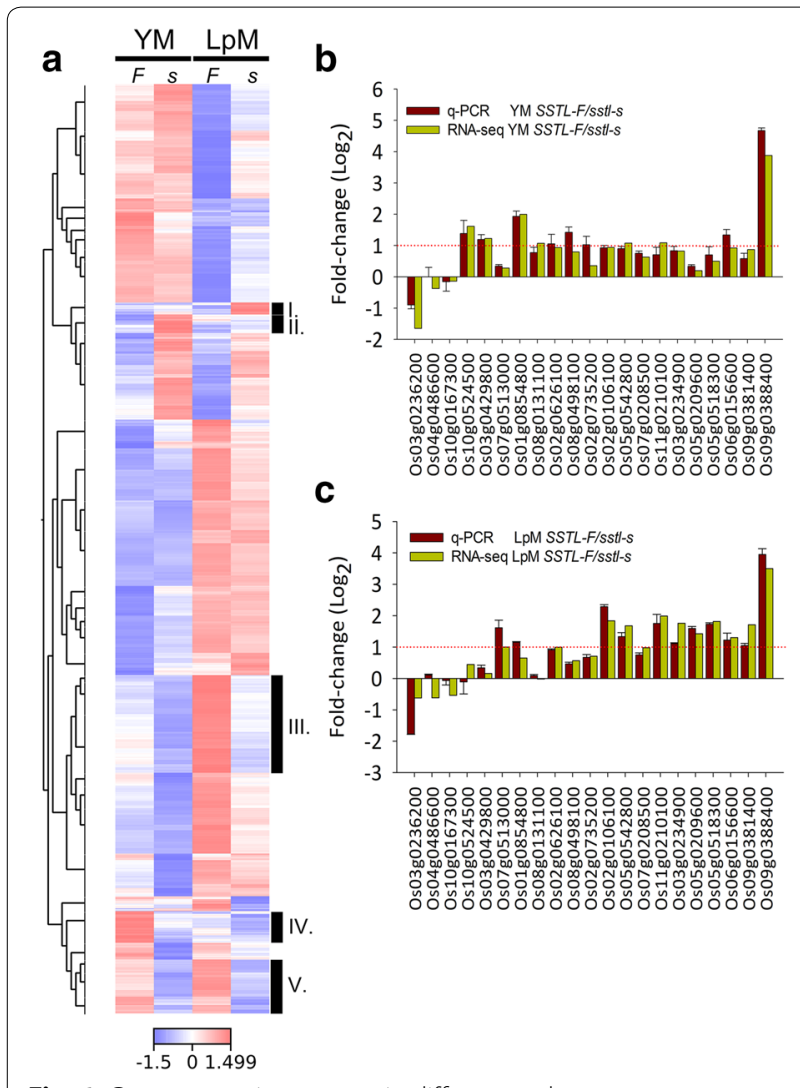

Fig. 6 Gene expression pattern in different anther stages. a Heat-map analysis of RNA-seq data in YM and LpM stage for fertile and sterile anthers. $\mathbf{b}$ Relative contribution of fold changes between RNA-seq and qPCR data in YM and $\mathbf{c} L \mathrm{LM}$. Gene expression of q-PCR data normalized to that of OsUBI, OsACT11, OsUBQ5, and eEF-1a. YM young microspores stage, LPM late pollen mitosis stage, I a cluster with specific upregulated genes of sstl-s in LpM, II a cluster with specific upregulated genes of sst-s in YM, III a cluster with specific upregulated genes of SSTL-F in LPM, IV a cluster with specific upregulated genes of SSTL-F in YM, $V$ a cluster of SSTL-F upregulated genes in both YM and LpM stages, $F$ fertile, $s$ sterile. Data are mean $\pm S D$

consistent with the cross section of sstl-s anthers (Fig. 3j, $o$ ). The statistical analysis of the anther locule area from $s s t l-s$ also gave similar findings of a small anther locule or unexpanded anther in sstl-s (Fig. 2e-h). This information suggests that the abnormal anther locule results in a shrunken and un-developmental anther in sstl-s.

\section{Transcriptomics analysis of the sstl-s mutant}

With the morphologic observations of the sstl-s mutant, we considered that processes such as starch accumulation, sporopollenin, and pollen wall structure as well as biosyntheses such as sucrose, secondary production, and lipid component metabolism must be involved in the pollen maturation process. To discuss thoroughly the biosynthesis pathways, we compared transcriptomics of different anther stages between SSTL-F and sstl-s (Fig. 6). The heat map illustrated five clusters with specific differentially expressed genes. Clusters I and II were upregulated genes from sstl-s in LpM and YM stages, clusters III and IV were specifically upregulated genes from SSTL-F in LpM or YM stages individually, and cluster V genes were upregulated in both YM and LPM stages from SSTL$F$ (Fig. 6a). From these five clusters, several genes listed in Additional file 5: Table S3 were selected for validation with real-time q-PCR analysis (Fig. 6b, c). The expression pattern between RNA-seq and q-PCR was similar and had almost equal $\log _{2}$ fold-change. The q-PCR expression of these selected genes also matched the heat map distribution in the five clusters; for example, genes in Os03g0236200, Os04g0486600, and Os10g0167300 were upregulated only in sstl-s; Os10g0524500, Os03g0429800, Os01g0854800 and Os08g0131100 of SSTL-F were significantly upregulated in YM with more than two-fold change on both RNA-seq and q-PCR; Os11g0210100, Os03g0234900, Os05g0209600, and Os05g0518300 of SSTL-F were particularly highly expressed in LpM; and Os02g0626100, Os02g0106100, Os05g0542800, and Os06g0156600 of SSTL-F had two-fold higher expression in both YM and LpM (Fig. 6b, c). Meanwhile, two late pollen preference genes, Os09g0381400 (similar to Ervatamin C) and Os09g0388400 (HAD-superfamily hydrolase-like), were also expressed in fertile pollen grains (Fig. 6b, c) (Moon et al. 2018). The expression of Os09g0388400 was 16-fold higher in fertile SSTL-F than $s s t l-s$, which indicated that the sterile $s s t l-s$ anther contained a high amount of defective pollen grains.

The transcriptomics analysis also revealed that the sterile $s s t l-s$ anther genes contained low expression of biosynthesis pathway genes such as xanthine dehydrogenase (Os03g0429800), which participates in purine metabolism; the catalytic cycle of cytochrome P450 (Os01g0854800 and Os08g0131100), involved in secondary metabolites synthesis for exine formation; class III peroxidase (Os11g0210100 and Os03g0234900), which uses electrons in ox-reduction reaction to manipulate phenolic compound synthesis and secondary metabolites; GDSL esterase (Os05g0209600, Os05g0518300, and Os06g0156600), related to lipolytic enzymes and thus controlling pollen wall structure; fructosyl transferase (Os02g0106100), participating in starch composition of mature pollen grains; and the polygalacturonases-like 9 (Os05g0542800), involved in carbohydrate metabolism of polysaccharides for intine utilization. We used Rice Anther Expression Plots analysis to confirm that these significant transcripts of 
pollen development were expressed during anther-specific stages (Additional file 6: Figure S3). For instance, genes that appear from later meiosis to uninucleate microspore stage were consistent with our data in the YM stage. No Pollen 1 (Os10g0524500), xanthine dehydrogenase (Os03g0429800), and cytochrome P450 86A7-2 (Os01g0854800) were specifically upregulated in YM only, which was identical to the pattern in Rice Anther Expression Plots analysis. Os02g0106100, Os05g0542800, Os11g0210100, and Os09g0388400, significant genes in LpM stage, also responded to the same stage of bicellular pollen and mature pollen stage as in Rice Anther Expression Plots.

\section{Discussion}

\section{Somaclonal variation might cause the sstl trait}

On cosegregation of the T-DNA insertion and sterile phenotype of two TRIM mutants M0024091 and M0017896, SUMO E3 ligase SIZ1 and bHLH142 were found to control male sterility via anther dehiscence and PCD of tapetum (Thangasamy et al. 2011; Ko et al. 2014). However, in the current study, the phenotype (sterility) and genotype (T-DNA insertion) did not cosegregate in the TRIM mutant M0037841. Previous studies have shown that rice T-DNA insertional mutants, such as Tos 17 and TRIM, show low tagging efficiency (Droc et al. 2013; Wei et al. 2016b; Wu et al. 2017). The transformation was frequently used to study both forward and reverse genetics in knockdown/knockout mutants, overexpression lines, and T-DNA activation tagging lines, etc. In rice transformation, the procedure included repetitive tissue culture steps such as rice embryogenic callus generation, antibiotic selection of callus, and seedling regeneration. This long-term cullus growth period may lead to somaclonal variation including single nucleotide polymorphism (SNP), indels, chromosome doubling, and chromosome translocations (Wei et al. 2016a). From 600 to 2000 SNPs/indels per plant may occur during rice regeneration and transformation in the TRIM mutants (Wei et al. 2016a). Thus, this M0037841 semisterile sstl mutation might be also caused by somaclonal variations during transformation.

From the developmental morphology of sstl progeny segregates, the completely sterile $s s t l-s$ line inherited the sterility and showed defects in anther locule and pollen grain. This kind of somaclonal variation might be applied to crop improvement with stable heritability and also may speed up the breeding process and replace traditional crossbreeding (Jain 2001). Additional file 2: Table S2 illustrates that 6 T-DNA insertional mutant lines have normal fertility. From
TRIM database information, we already know that the T-DNA insertion site of M0037841 locates in the exon of a Mei2-like protein (Os02g0517531). Mei2-like of Arabidopsis is a regulator of meiosis and expressed in gametes of pollens (Kaur et al. 2006). The rice genome contains 6 OsMei2-like genes (Anderson et al. 2004). Thus, M0037841 might maintain fertility because of the gene abundance.

\section{Defective events start in microsporangia in the sstl-s mutant}

From the cytological observation of anther morphology, we investigated the microspores of the sterile mutant sstl-s from YM to Mp stages and discovered that the early stage of microspore development is unusual and defective (Fig. $3 \mathrm{f}-\mathrm{o}$ ). The expression of the later pollen preference gene HAD-superfamily hydrolase-like (Os09g0388400) is extremely high in fertile SSTL-F, which indicates a severe defect in this expression in the mutant sstl-s. Significant downregulation of HADsuperfamily hydrolase-like may occur because sstl-s has empty defective pollen or even no microspores produced in anther locules (Fig. 3f-o). Moreover, the mutant sstl-s has abnormal and defective anthers in slender twig-like or even "X"-like shapes during microsporangia development stage (Additional file 4: Figure S2). A recent study of the rice SQUAMOSA PROMOTER-BINDING PROTEIN-LIKE 6 (SPL6) mutant spl6-1 also showed a cell death phenotype in the panicle and the distorted anther in a "X"-like shape, signaling damaged microsporangia development (Wang et al. 2018). OsSPL6 directly repressed inositol-requiring enzyme 1 (IRE1) expression as a transcriptional repressor. Also, overexpressed IRE1 was an endoplasmic reticulum stress sensor resulting in a cell death phenotype of panicle (Wang et al. 2018). Un-developmental microsporangia of the spl6-1 mutant led to sterility, including white spikelet and yield loss; the mutant also showed a significant reduction in panicle length, spikelet number, seed setting rate, and 1000 grain-weight. However, the spl6-1 mutant had no effect on plant height and number of panicle branches and thus was similar to sstl-s. In Arabidopsis, the expression of SPL1 and SPL12 increased heat tolerance during the reproductive stage and promoted seed production under heat stress. Without functional SPL1 and SPL12, the inflorescences of Arabidopsis showed dead cells and seeds were aborted (Chao et al. 2017). From morphological characterization, the microsporangia development of $s s t l-s$ has been destroyed, similar to the anthers of the spl6-1 mutant with an " $\mathrm{X}$ "-shape of early developmental anthers. From the genome sequence data, we confirm that sstl-s has no mutation in OsSPL6 (data not shown). The defective pollen and the "X"-like defective anther of 
sstl-s imply that microsporangia development is defective; thus, no sporogenous cells are produced in abnormal anther locules during early anther development.

\section{Several biosynthetic pathways are affected in sstl-s}

Our studies indicate the pollen in the mutant sstl-s is severely reduced, with abnormal pollen wall in exine and intine, shrunken pollen grains, low pollen viability and no pollen grain germination. From comparative transcription analysis, the RNA-seq data was substantiated by q-PCR assay illustrating that our silicon data are as reliable as the actual expression on real-time q-PCR (Fig. 6b, c). We evaluated the difference in transcriptomics between sstl-s and SSTL-F as compared with reference homologs from the KEGG database and tried to understand the multiple impacts on sterility. From the 5 significant transcript heat map clusters (Fig. 6a) and EXPath Tool analysis (Additional file 7: Table S4), clusters I and II revealed that transcripts of sstl-s are involved in degradation of carbon metabolism and amino acid metabolism, such as glyceraldehyde-3-phosphate dehydrogenase (GAPDH) (Os04g0486600), enolase 2 gene (Os10g0167300), and glutamate decarboxylase 3 (OsGAD3) (Os03g0236200). In gluconeogenesis, GAPDH participates in glycolysis at the 6th step to break down glucose for energy contribution and enolase 2 catalyzes 2-phosphoglycerate (2-PG) to phosphoenolpyruvate from the 9th or second to the last step of glycolysis (Yang et al. 2015; Swain et al. 2017). The expression of OsGAD3, which catalyzes glutamate to $\gamma$-aminobutyric acid for glutamate degradation (Zhang et al. 2007; El-Kereamy et al. 2012), was increased in sstl-s. In clusters III, IV, and $\mathrm{V}$, the upregulated genes of fertile SSTL-F share similar functions, such as phenylalanine metabolism, cutin/ suberine/wax biosynthesis, secondary metabolites, flavone/flavonol biosynthesis, and starch/sucrose metabolism (Additional file 7: Table S4). We also performed MapMen analysis and illustrated that biosynthetic pathways in cell wall, lipids, secondary metabolism, and starch are affected in sstl-s (Fig. 7). Integral pollen exine was controlled by genes related to fatty acid components, secondary products, and cutin/wax biosynthesis for pollen wall conformation (Quilichini et al. 2015; Shi et al. 2015). Therefore, metabolic events are important in sporophytic development. For instance, a well-developed exine of pollen has a tightly bound fatty acid-like sporopollenin that organizes a bridge-like structure and then the fatty acid assembles aliphatic derivatives such as cutin and wax to form the pollen wall and anther cuticle (Li et al. 2010; Li-Beisson et al. 2013). These functional metabolisms in lipids and fatty acid are consistent with the observation of a rich lipid structure in SSTL-F exine
TEM ultrathin section characterizations (Fig. 4). Meanwhile, lipid participates in phenolic secondary metabolites in flavonoid production. The flavonoids function as antioxidants to protect the plant against abiotic stress and biotic stress to clean superoxide anions $\mathrm{O}_{2}{ }^{-}$, hydrogen peroxide $\left(\mathrm{H}_{2} \mathrm{O}_{2}\right)$, hydroxyl radicals $\left(\mathrm{OH}^{-}\right)$, and singlet oxygen $\left({ }^{1} \mathrm{O}_{2}\right)$, etc. when these oxygen species (ROS) accumulate under stress (Hernández et al. 2009). In rice flowering stage, flavonoids protect anthers and pollens against ultraviolet damage and increase the bright yellow color to attract pollinators (Thompson et al. 2010; Ning et al. 2018). Our data illustrate that sterile $s s t l-s$ shows downregulated flavonoid synthesis-related genes (Fig. 7 and Additional file 7: Table S4). Figure 2b, c also show white anthers and pollen grains, indicating no flavonoid accumulation. A male-sterile maize mutant of irregular pollen exine 1 (ipe1) also had defective pollen grains and abnormal pollen exine with low wax and flavonoid accumulation (Chen et al. 2017). With the secondary metabolomics essential for pollen development, any defect of these controlling genes may cause sterility and loss of yield production. The oxidative phosphorylation pathway may regulate secondary metabolites production and Arabidopsis soluble pyrophosphatases ( $P P a 3$ ) specifically present in root hairs and pollen tissues (Gutiérrez-Luna et al. 2018; Segami et al. 2018). Our transcriptional data also demonstrate that pyrophosphatase-related genes are upregulated only in fertile anthers and they might participate in a secondary metabolic pathway for pollen wall structure. The starch accumulation of mature pollen is initiated from glucose-6-phosphate (Glc-6-P), which converts to Glc-1-P, and Glc-1-P then converts to ADP-glucose in the amyloplasts that depend on plastidic ADP-Glc synthesis (Lee et al. 2016). The starch in pollen grains may offer energy for pollen grains in maturation and germination. The $\mathrm{I}_{2} \mathrm{KI}$ staining (Fig. 2k) of wild-type and mutant pollen agrees with the expression difference in starch synthesis genes (Fig. 7 and Additional file 7: Table S4).

We also investigated several genes related to male-sterile phenotype. Rice No Pollen 1 (NP1) (Os10g0524500) of fertile pollen is expressed up to threefold that of the sterile sstl-s (Fig. 6b and Additional file 5: Table S3). NP1 regulates anther size and Ubisch body formation to contribute a pollen exine structure and manipulate fertility in pollen grains (Liu et al. 2017). The $n p 1-4$ mutant has an irregular pollen granule, reductive cutin, and less cuticular wax in exine formation (Liu et al. 2017). Rice lipid hydrolysis-related genes GDSLs are upregulated in mature pollen of SSTL-F (Fig. 6b-c and Additional file 5: Table S3). One GDSL was confirmed from Brassica rapa, known as extracellular lipase 6 (BrEXL6), which functions as a pollen development-related gene. Another case 


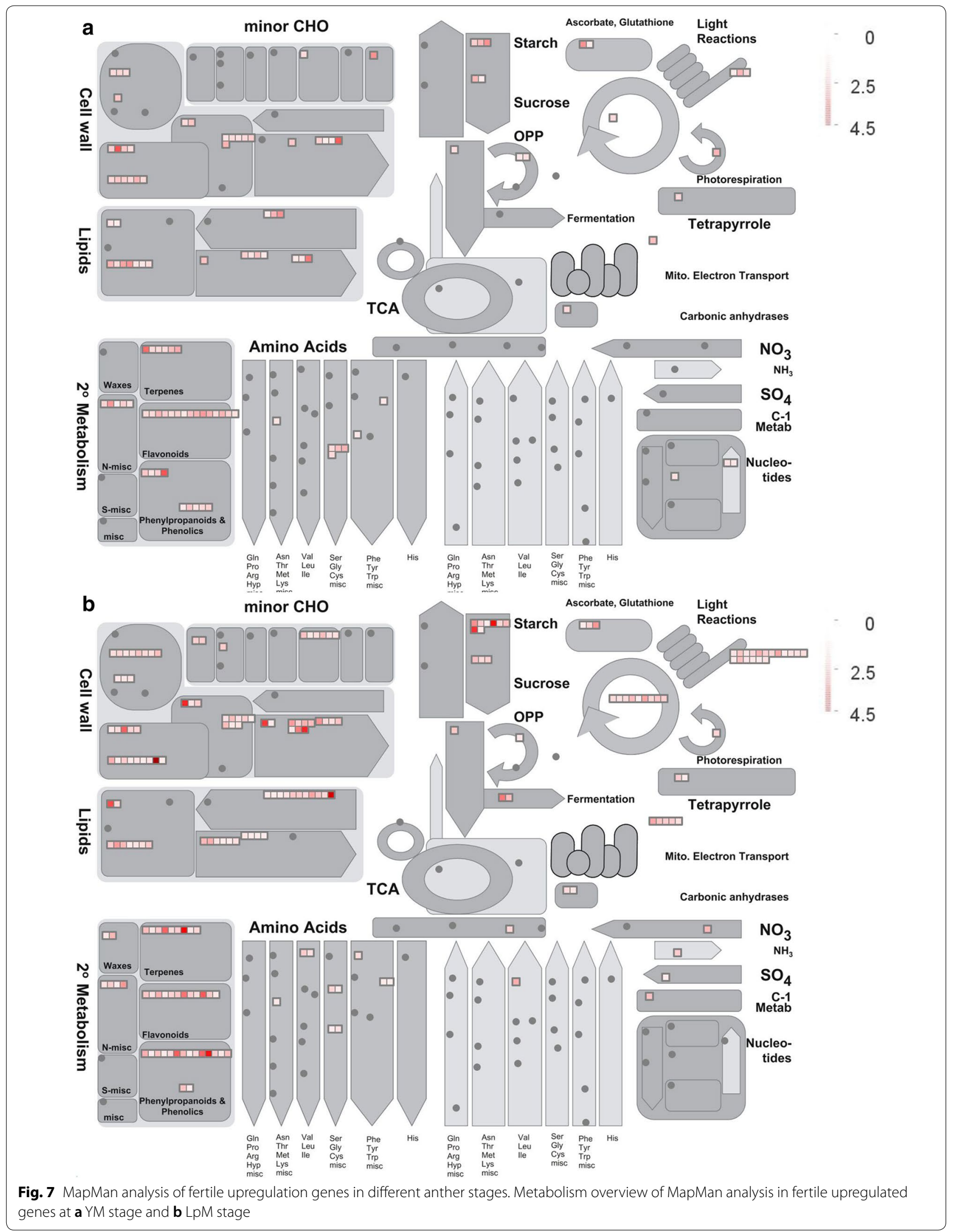


was $Z m M s 30$, a maize GDSL, which was found essential for male fertility because the knockout $Z m M s 30$ mutant showed a disordered pollen wall and defective pollen grains (Ji et al. 2017; An et al. 2019).

\section{Conclusion}

Here we report an untagged T-DNA insertional mutant M0037841 that has defective pollen and abnormal anthers from its sstl progeny segregaters. The abnormal anther locule is related to the damaged microsporangia and results in no microspore generation. The defective anther locule of $s s t l-s$ also illustrates the importance of the anther tapetum, which provides lipid-like sporopollenin for pollen maturation. Transcripts of sterile sstl-s are downregulated in several secondary-metabolism biosynthesis pathways and lead to irregular exine and absent intine in sstl-s. This information reveals the defective pollen grains of $s s t l-s$ and coincides with the irregular pollen wall and loss of pollen viability. Comparative transcriptomics analysis illustrates that the mechanism of male sterility is related to biosynthetic pathways for cell wall, lipids, secondary metabolism, and starch accumulation. We illustrate the importance of microsporangia development and male fertility of microspores. A series of morphological observations of mutant sstl-s anther demonstrated that the defective pollen grains are caused by unproduced intine and unfunctional exine of the pollen wall, then the defective pollen of sstl-s do not germinate and become sterile.

\section{Additional files}

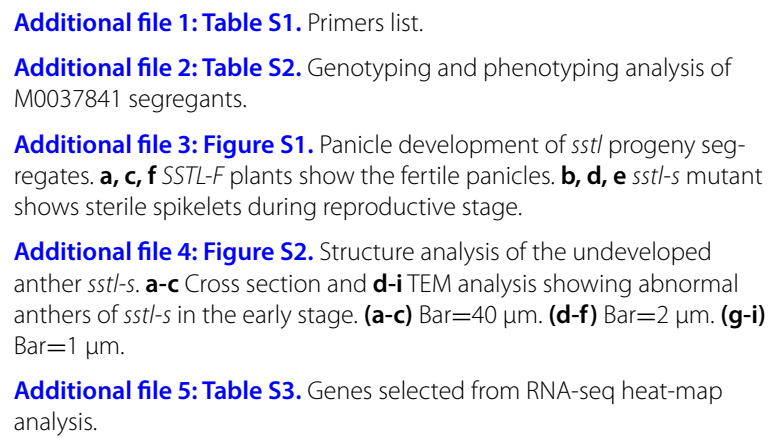

Additional file 3: Figure S1. Panicle development of sst/ progeny segregates. $\mathbf{a}, \mathbf{c}, \mathbf{f} S S T L-F$ plants show the fertile panicles. b, d, e sstl-s mutant shows sterile spikelets during reproductive stage.

Additional file 4: Figure S2. Structure analysis of the undeveloped anther sst--s. a-c Cross section and $\mathbf{d}$-i TEM analysis showing abnormal anthers of sstl-s in the early stage. (a-c) Bar=40 $\mu \mathrm{m}$. (d-f) $B a r=2 \mu \mathrm{m}$. (g-i) $\mathrm{Bar}=1 \mu \mathrm{m}$.

Additional file 5: Table S3. Genes selected from RNA-seq heat-map analysis.

Additional file 6: Figure S3. The differential expressed genes of SSTL-F and sstl-s during anther developing stages using Rice Anther Expression Plots (https://www.cpib.ac.uk/anther/riceindex.html). PM=Premeiosis; $\mathrm{M}=$ Meiosis; $\mathrm{UM}=$ Uninucleate Microspore; $\mathrm{BP}=$ Bicellular Pollen; $\mathrm{TP}=$ Tricellular pollen; $\mathrm{MP}=$ Mature Pollen

Additional file 7: Table S4. Prediction of gene function in RNA-seq heatmap analysis result.

\section{Abbreviations}

bHLH: basic helix-loop-helix; EAT1: ETERNAL TAPETUM1; EMS1: EXCESS MICROSPOROCYTES1; EpM: early pollen mitosis stage; GDSL: Gly-Asp-Ser-Leu; GM filed: genetically modified plants isolation field; $\mathrm{I}_{2}-\mathrm{Kl}$ : iodine-potassium iodide; LpM: late pollen mitosis stage; Mp: mature pollen stage; NP1: Rice No Pollen 1; PCD: programmed cell death; PMC: pollen mother cells; PPC: primary parietal cells; PS: primary sporogenous; SEM: scanning electron microscopy; SNP: single nucleotide polymorphism; SPC: secondary parietal layers; SPL: SQUAMOSA PROMOTER-BINDING PROTEIN-LIKE; sstl: semi-sterile mutant; SSTLF: fertile plants of sstl progeny segregates; sstl-s: sterile plants of sstl progeny segregates; sstl-ss: semi-sterile plants of sstl progeny segregates; TARI: Taiwan Agricultural Research Institute; TDR: TAPETUM DEGENERATION RETARDATION; TEM: transmission electron microscope; TPD1:TAPETUM DETERMINANT1; TRIM: Taiwan Rice Insertional Mutagenesis; VP: vacuolated pollen stage; YM: young microspore stage.

\section{Acknowledgements}

We thank Ms. Lie-Hong Wu for maintenance of greenhouse plants, and Laura Smales (BioMedEditing, Toronto, Canada) for English editing.

\section{Authors' contributions}

$\mathrm{CLC}$ and YICH are responsible for the experimental design. All sample collection was prepared by CLC. JCS and YCT were in charge of $\mathrm{T}_{2}$ population sample management. $\mathrm{HHH}$ and $\mathrm{MHL}$ performed the rice cultivation in TARI. CLC performed molecular analyses of PCR-genotyping, gene expression and bioinformatics analysis of transcriptomic data. YCL performed pollen staining analysis. WNJ prepared TEM samples for observation. CLC observed samples and took the photographs. CLC consolidated results and wrote the manuscript. YIH and MCC edited the manuscript. All authors read and approved the final manuscript.

\section{Funding}

This work was supported by Academia Sinica, Taiwan to YICH.

\section{Availability of data and materials}

Not applicable.

Ethics approval and consent to participate Not applicable.

\section{Consent for publication}

Not applicable.

\section{Competing interests}

The authors declare that they have no competing interests.

\section{Author details}

${ }^{1}$ Department of Agronomy, National Taiwan University, Taipei 106, Taiwan. ${ }^{2}$ Institute of Plant and Microbial Biology, Academia Sinica, Nankang, Taipei 115 , Taiwan. ${ }^{3}$ Crop Science Division, Taiwan Agricultural Research Institute, Taichung 413, Taiwan. ${ }^{4}$ Department of Life Science, National Taiwan University, Taipei 106, Taiwan. ${ }^{5}$ Department of Agronomy, National Chiayi University, Chiayi 600, Taiwan.

Received: 17 April 2019 Accepted: 30 June 2019

Published online: 10 July 2019

\section{References}

An X, Dong Z, Tian Y, Xie K, Wu S, Zhu T, Zhang D, Zhou Y, Niu C, Ma B, Hou Q, Bao J, Zhang S, Li Z, Wang Y, Yan T, Sun X, Zhang Y, Li J, Wan X (2019) ZmMs30 encoding a novel GDSL lipase is essential for male fertility and valuable for hybrid breeding in maize. Mol Plant 12:343-359. https://doi. org/10.1016/j.molp.2019.01.011

Anderson GH, Alvarez NDG, Gilman C, Jeffares DC, Trainor VCW, Hanson MR, Veit B (2004) Diversification of genes encoding Meiz-Like RNA binding proteins in plants. Plant Mol Biol 54:653-670. https://doi.org/10.1023/ b:plan.0000040819.33383.b6 
Caffall KH, Mohnen D (2009) The structure, function, and biosynthesis of plant cell wall pectic polysaccharides. Carbohydr Res 344:1879-1900. https:// doi.org/10.1016/j.carres.2009.05.021

Cai W, Zhang D (2018) The role of receptor-like kinases in regulating plant male reproduction. Plant Reprod 31:77-87. https://doi.org/10.1007/s0049 7-018-0332-7

Chang Z, Jin M, Yan W, Chen H, Qiu S, Fu S, Xia J, Liu Y, Chen Z, Wu J, Tang X (2018) The ATP-binding cassette (ABC) transporter OsABCG3 is essential for pollen development in rice. Rice 11(58):1-15. https://doi.org/10.1186/ s12284-018-0248-8

Chao LM, Liu YQ, Chen DY, Xue XY, Mao YB, Chen XY (2017) Arabidopsis transcription factors SPL1 and SPL12 confer plant thermotolerance at reproductive stage. Mol Plant 10:735-748. https://doi.org/10.1016/j. molp.2017.03.010

Chen X, Zhang H, Sun H, Luo H, Zhao L, Dong Z, Yan S, Zhao C, Liu R, Xu C, Li S, Chen H, Jin W (2017) IRREGULAR POLLEN EXINE1 is a novel factor in anther cuticle and pollen exine formation. Plant Physiol 173:307-325. https://doi.org/10.1104/pp.16.00629

Choi H, Jin JY, Choi S, Hwang JU, Kim YY, Suh MC, Lee Y (2011) An ABCG/WBCtype $A B C$ transporter is essential for transport of sporopollenin precursors for exine formation in developing pollen. Plant J 65:181-193. https://doi. org/10.1111/j.1365-313x.2010.04412.x

Daku RM, Rabbi F, Buttigieg J, Coulson IM, Horne D, Martens G, Ashton NW, Suh DY (2016) PpASCL, the Physcomitrella patens anther-specific chalcone synthase-like enzyme implicated in sporopollenin biosynthesis, is needed for integrity of the moss spore wall and spore viability. PLOS ONE 11(1):e0146817. https://doi.org/10.1371/journal.pone.0146817

Droc G, An G, Hsing YI, Hirochika H, Pereira A, Undaresan CS, Han CD, Upadhyaya N, Ramachandran S, Comai L, Leung H, Guiderdoni E (2013) Mutant resources for the functional analysis of the rice genome. In: Wing $R$, Zhang Q (eds) Genetics and genomics of rice, vol 5. Springer, Berlin, pp $81-115$

El-Kereamy A, Bi YM, Ranathunge K, Beatty PH, Good AG, Rothstein SJ (2012) The Rice R2R3-MYB transcription factor OSMYB55 is involved in the tolerance to high temperature and modulates amino acid metabolism. PLoS ONE 7(12):e52030. https://doi.org/10.1371/journal.pone.0052030

Guo C, Ge X, Ma H (2013) The rice OsDIL gene plays a role in drought tolerance at vegetative and reproductive stages. Plant Mol Biol 82:239-253. https:// doi.org/10.1007/s11103-013-0057-9

Gutiérrez-Luna FM, Hernández-Domínguez EE, Valencia-Turcotte LG, Rodríguez-Sotres R (2018) Review: "Pyrophosphate and pyrophosphatases in plants, their involvement in stress responses and their possible relationship to secondary metabolism". Plant Sci 267:11-19. https://doi. org/10.1016/j.plantsci.2017.10.016

Hernández I, Alegre L, Breusegem FV, Munné-Bosch S (2009) How relevant are flavonoids as antioxidants in plants? Trends Plant Sci 14:125-132. https:// doi.org/10.1016/j.tplants.2008.12.003

Huang MD, Wei FJ, Wu CC, Hsing YI, Huang AH (2009) Analyses of advanced rice anther transcriptomes reveal global tapetum secretory functions and potential proteins for lipid exine formation. Plant Physiol 149:694-707. https://doi.org/10.1104/pp.108.131128

Huang J, Zhang T, Linstroth L, Tillman Z, Otegui MS, Owen HA, Zhao D (2016) Control of anther cell differentiation by the small protein ligand TPD1 and its receptor EMS1 in Arabidopsis. PLoS Genet 12(8):e1006147. https://doi. org/10.1371/journal.pgen.1006147

Jain SM (2001) Tissue culture-derived variation in crop improvement. Euphytica 118:153-166. https://doi.org/10.1023/a:1004124519479

Ji R, Wang H, Xin X, Peng S, Hur Y, Li Z, Feng H (2017) BrEXL6, a GDSL lipase gene of Brassica rapa, functions in pollen development. Biol Plant 61:685-692. https://doi.org/10.1007/s10535-017-0735-6

Jung KH, Han MJ, Lee DY, Lee YS, Schreiber L, Franke R, Faust A, Yephremov A, Saedler H, Kim YW, Hwang I, An G (2006) Wax-deficient anther1 is involved in cuticle and wax production in rice anther walls and is required for pollen development. Plant Cell 18:3015-3032. https://doi.org/10.1105/ tpc.106.042044

Kaur J, Sebastian J, Siddiqi I (2006) The Arabidopsis-mei2-Like genes play a role in meiosis and vegetative growth in Arabidopsis. Plant Cell 18:545-559. https://doi.org/10.1105/tpc.105.039156

Kelliher T, Egger RL, Zhang H, Walbot V (2014) Unresolved issues in pre-meiotic anther development. Front Plant Sci 5(347):1-9. https://doi.org/10.3389/ fpls.2014.00347
Ko SS, Li MJ, Sun-Ben KuM, Ho YC, Lin YJ, Chuang MH, Hsing HX, Lien YC, Yang HT, Chang HC, Chan MT (2014) The bHLH142 transcription factor coordinates with TDR1 to modulate the expression of EAT1 and regulate pollen development in rice. Plant Cell 26:2486-2504. https://doi.org/10.1105/ tpc.114.126292

Lee S-K, Eom J-S, Hwang S-K, Shin D, An G, Okita TW, Jeon J-S (2016) Plastidic phosphoglucomutase and ADP-glucose pyrophosphorylase mutants impair starch synthesis in rice pollen grains and cause male sterility. J Exp Bot 67:5557-5569. https://doi.org/10.1093/jxb/erw324

Li N, Zhang DS, Liu HS, Yin CS, Li XX, Liang WQ, Yuan Z, Xu B, Chu HW, Wang J, Wen TQ, Huang H, Luo D, Ma H, Zhang DB (2006) The Rice Tapetum Degeneration Retardation gene is required for tapetum degradation and anther development. Plant Cell 18:2999-3014. https://doi.org/10.1105/ tpc.106.044107

Li H, Pinot F, Sauveplane V, Werck-Reichhart D, Diehl P, Schreiber L, Franke R, Zhang P, Chen L, Gao Y, Liang W, Zhang D (2010) Cytochrome P450 family member CYP704B2 catalyzes the \& \#x03C9;-hydroxylation of fatty acids and is required for anther cutin biosynthesis and pollen exine formation in rice. Plant Cell 22:173-190. https://doi.org/10.1105/tpc.109.070326

Li H, Yuan Z, Vizcay-Barrena G, Yang C, Liang W, Zong J, Wilson ZA, Zhang D (2011) PERSISTENT TAPETAL CELL1 encodes a PHD-finger protein that is required for tapetal cell death and pollen development in rice. Plant Physiol 156:615-630. https://doi.org/10.1104/pp.111.175760

Li Y, Li D, Guo Z, Shi Q, Xiong S, Zhang C, Zhu J, Yang Z (2016) OsACOS12, an orthologue of Arabidopsis acyl-CoA synthetase5, plays an important role in pollen exine formation and anther development in rice. BMC Plant Biol 16:256. https://doi.org/10.1186/s12870-016-0943-9

Li-Beisson Y, Shorrosh B, Beisson F, Andersson MX, Arondel V, Bates PD, Baud S, Bird D, Debono A, Durrett TP, Franke RB, Graham IA, Katayama K, Kelly AA, Larson T, Markham JE, Miquel M, Molina I, Nishida I, Rowland O, Samuels L, Schmid KM, Wada H, Welti R, Xu C, Zallot R, Ohlrogge J (2013) Acyl-lipid metabolism. The Arabidopsis book, vol 11. American Society of Plant Biologists, Washington, p e0161. https://doi.org/10.1199/tab.0161

Liu Z, Bao W, Liang W, Yin J, Zhang D (2010) Identification of gamyb-4 and analysis of the regulatory role of GAMYB in rice anther development. J Integr Plant Biol 52:670-678. https://doi.org/10.1111/j.1744-7909.2010.00959.x

Liu Z, Lin S, Shi J, Yu J, Zhu L, Yang X, Zhang D, Liang W (2017) Rice No Pollen 1 (NP 1) is required for anther cuticle formation and pollen exine patterning. Plant J 91:263-277

Moon S, Kim SR, Zhao G, Yi J, Yoo Y, Jin P, Lee SW, Jung KH, Zhang D, An G (2013) Rice GLYCOSYLTRANSFERASE1 encodes a glycosyltransferase essential for pollen wall formation. Plant Physiol 161:663-675. https://doi. org/10.1104/pp.112.210948

Moon S, Oo MM, Kim B, Koh H-J, Oh SA, Yi G, An G, Park SK, Jung KH (2018) Genome-wide analyses of late pollen-preferred genes conserved in various rice cultivars and functional identification of a gene involved in the key processes of late pollen development. Rice 11:28. https://doi. org/10.1186/s12284-018-0219-0

Ning L, Lin Z, Gu J, Gan L, Li Y, Wang H, Miao L, Zhang L, Wang B, Li M (2018) The initial deficiency of protein processing and flavonoids biosynthesis were the main mechanisms for the male sterility induced by SX-1 in Brassica napus. BMC Genom 19:806. https://doi.org/10.1186/s1286 4-018-5203-y

Pu CX, Han YF, Zhu S, Song FY, Zhao Y, Wang CY, Zhang YC, Yang Q, Wang J, Bu SL, Sun L, Zhang SW, Zhang SQ, Sun DY, Sun Y (2017) The rice receptorlike kinases DWARF AND RUNTISH SPIKELET1 and 2 repress cell death and affect sugar utilization during reproductive development. Plant Cell 29:70-89. https://doi.org/10.1105/tpc.16.00218

Quilichini TD, Grienenberger E, Douglas CJ (2015) The biosynthesis, composition and assembly of the outer pollen wall: a tough case to crack. Phytochemistry 113:170-182. https://doi.org/10.1016/j.phytochem.2014.05.002

Raghavan V (1988) Anther and pollen development in rice (Oryza sativa). Am J Bot 75:183-196

Ruggiero F, Bedini G (2018) Systematic and morphologic survey of orbicules in allergenic angiosperms. Aerobiologia 34:405-422. https://doi. org/10.1007/s10453-018-9522-x

Segami S, Tomoyama T, Sakamoto S, Gunji S, Fukuda M, Kinoshita S, Mitsuda $\mathrm{N}$, Ferjani A, Maeshima M (2018) Vacuolar $\mathrm{H}^{+}$-pyrophosphatase and cytosolic soluble pyrophosphatases cooperatively regulate pyrophosphate levels in Arabidopsis thaliana. Plant Cell 30:1040-1061. https://doi. org/10.1105/tpc.17.00911 
Shi J, Cui M, Yang L, Kim Y-J, Zhang D (2015) Genetic and biochemical mechanisms of pollen wall development. Trends Plant Sci 20:741-753. https:// doi.org/10.1016/j.tplants.2015.07.010

Swain DM, Sahoo RK, Srivastava VK, Tripathy BC, Tuteja R, Tuteja N (2017) Function of heterotrimeric G-protein y subunit RGG1 in providing salinity stress tolerance in rice by elevating detoxification of ROS. Planta 245:367-383. https://doi.org/10.1007/s00425-016-2614-3

Thangasamy S, Guo CL, Chuang MH, Lai MH, Chen J, Jauh GY (2011) Rice SIZ1, a SUMO E3 ligase, controls spikelet fertility through regulation of anther dehiscence. New Phytol 189:869-882. https://doi.org/10.111 1/j.1469-8137.2010.03538.x

Thompson EP, Wilkins C, Demidchik V, Davies JM, Glover BJ (2010) An Arabidopsis flavonoid transporter is required for anther dehiscence and pollen development. J Exp Bot 61:439-451. https://doi.org/10.1093/jxb/erp312

Verma N (2019) Transcriptional regulation of anther development in Arabidopsis. Gene 689:202-209. https://doi.org/10.1016/j.gene.2018.12.022

Walbot V, Egger RL (2016) Pre-meiotic anther development: cell fate specification and differentiation. Annu Rev Plant Biol 67:365-395. https://doi. org/10.1146/annurev-arplant-043015-111804

Wang Y, Lin YC, So J, Du Y, Lo C (2013) Conserved metabolic steps for sporopollenin precursor formation in tobacco and rice. Physiol Plant 149:13-24. https://doi.org/10.1111/ppl.12018

Wang QL, Sun AZ, Chen ST, Chen LS, Guo FQ (2018) SPL6 represses signalling outputs of ER stress in control of panicle cell death in rice. Nat Plants 4:280-288. https://doi.org/10.1038/s41477-018-0131-z

Wei FJ, Kuang LY, Oung HM, Cheng SY, Wu HP, Huang LT, Tseng YT, Chiou WY, Hsieh-Feng V, Chung CH, Yu SM, Lee LY, Gelvin SB, Hsing YIC (2016a) Somaclonal variation does not preclude using rice transformants for genetic screening. Plant J 85:648-659. https://doi.org/10.1111/tpj.13132

Wei FJ, Tsai YC, Hsu YM, Chen YA, Huang CT, Wu HP, Huang LT, Lai MH, Kuang LY, Lo SF, Yu SM, Lin YR, Hsing YIC (2016b) Lack of genotype and phenotype correlation in a rice T-DNA tagged line is likely caused by introgression in the seed source. PLOS ONE 11(5):e0155768. https://doi.org/10.1371/journ al.pone.0155768

Wu HP, Wei FJ, Wu CC, Lo SF, Chen LJ, Fan MJ, Chen S, Wen IC, Yu SM, Ho THD, Lai MH, Hsing YIC (2017) Large-scale phenomics analysis of a T-DNA tagged mutant population. GigaScience 6:1-7. https://doi.org/10.1093/ gigascience/gix055
Xu T, Zhang C, Zhou Q, Yang ZN (2016) Pollen wall pattern in Arabidopsis. Sci Bull 61:832-837. https://doi.org/10.1007/s11434-016-1062-6

Yang X, Wu D, Shi J, He Y, Pinot F, Grausem B, Yin C, Zhu L, Chen M, Luo Z, Liang W, Zhang D (2014) Rice CYP703A3, a cytochrome P450 hydroxylase, is essential for development of anther cuticle and pollen exine. J Integr Plant Biol 56:979-994. https://doi.org/10.1111/jipb.12212

Yang T, Wang L, Li C, Liu Y, Zhu S, Qi Y, Liu X, Lin Q, Luan S, Yu F (2015) Receptor protein kinase FERONIA controls leaf starch accumulation by interacting with glyceraldehyde-3-phosphate dehydrogenase. Biochem Biophys Res Commun 465:77-82. https://doi.org/10.1016/j.bbrc.2015.07.132

Yang L, Qian X, Chen M, Fei Q, Meyers BC, Liang W, Zhang D (2016) Regulatory role of a receptor-like kinase in specifying anther cell identity. Plant Physiol 171:2085-2100. https://doi.org/10.1104/pp.16.00016

Yang X, Li G, Tian Y, Song Y, Liang W, Zhang D (2018) A rice glutamyl-tRNA synthetase modulates early anther cell division and patterning. Plant Physiol 177:728-744. https://doi.org/10.1104/pp.18.00110

Zhang D, Wilson ZA (2009) Stamen specification and anther development in rice. Chin Sci Bull 54:2342-2353. https://doi.org/10.1007/s1143 4-009-0348-3

Zhang $H$, Yao H, Chen F, Wang X (2007) Purification and characterization of glutamate decarboxylase from rice germ. Food Chem 101:1670-1676. https://doi.org/10.1016/j.foodchem.2006.04.027

Zhang D, Liang W, Yin C, Zong J, Gu F, Zhang D (2010) OsC6, encoding a lipid transfer protein, is required for postmeiotic anther development in rice. Plant Physiol 154:149-162. https://doi.org/10.1104/pp.110.158865

Zhang D, Luo X, Zhu L (2011) Cytological analysis and genetic control of rice anther development. J Genet Genom 38:379-390. https://doi. org/10.1016/j.jgg.2011.08.001

\section{Publisher's Note}

Springer Nature remains neutral with regard to jurisdictional claims in published maps and institutional affiliations.

\section{Submit your manuscript to a SpringerOpen ${ }^{\circ}$ journal and benefit from:}

- Convenient online submission

- Rigorous peer review

- Open access: articles freely available online

- High visibility within the field

- Retaining the copyright to your article

Submit your next manuscript at $\boldsymbol{\Delta}$ springeropen.com 